\title{
Six year follow up of lung function in men occupationally exposed to formaldehyde
}

\author{
A J Nunn, A A Craigen, J H Darbyshire, K M Venables, A J Newman Taylor
}

\section{Abstract}

The long term effects of formaldehyde on the respiratory tract have been investigated in a group of 164 workers exposed daily to the chemical during the production of urea formaldehyde resin, together with 129 workers not exposed to free formaldehyde. Exposure was classified as high (corresponding to an eight hour time weighted exposure of more than $2.0 \mathrm{ppm})$, medium (0.6 to $2.0 \mathrm{ppm})$, or low $(0 \cdot 1$ to $0.5 \mathrm{ppm})$. Twenty five per cent of workers had had high exposure at some time and $17 \%$ moderate exposure. Both the exposed and unexposed groups had an annual assessment that included lung function. The proportion with self reported respiratory symptoms was similar in the two groups, $12 \%$ and $16 \%$ reporting breathlessness on hurrying and $26 \%$ and $20 \%$ wheezing. The initial forced expiratory volume in one second $\left(F E V_{1}\right)$ was within 0.51 (approximately one standard deviation (SD)) of the predicted value (by age and height) in $65 \%$ of the exposed and $59 \%$ of unexposed workers and more than 0.51 below the predicted value in $9 \%$ of exposed and $11 \%$ of unexposed workers. The mean decline in $\mathrm{FEV}_{1}$ was $42 \mathrm{ml}$ a year (SD 45) in the exposed group and $41 \mathrm{ml}$ a year in the unexposed group (SD $40 \mathrm{ml}$ a year). The rate of decline showed the expected association with smoking in the unexposed group, but in the exposed group the mean rate of decline in the never smokers was similar to that in current smokers. There were, however, relatively few never smokers and considerable variation in the rates of decline. In the exposed group no association was found between the rate of decline and indices of exposure to formaldehyde. Thus there is no evidence from

National Heart and Lung Institute, Brompton Hospital, London SW3 6HP

A J Nunn, J H Darbyshire, K M Venables, A J Newman Taylor

Ciba-Geigy Plastics, Duxford

A A Craigen this study of an excess of respiratory symptoms or decline in lung function in the workers exposed to formaldehyde. The similar rate of decline of FEV, however in never smokers and smokers of the exposed group is consistent with findings of other studies for workers exposed to formaldehyde and to toluene di-isocyanate.

Formaldehyde is a water soluble gas used in a variety of industries. It is irritant to the skin and mucous membranes, ${ }^{1}$ and is reported to cause asthma. ${ }^{2}$ After the introduction of urea formaldehyde foam insulation in the late 1970 s concern arose about possible adverse effects. ${ }^{34}$ We decided, therefore, to investigate the long term effects of formaldehyde on the respiratory tract by examining symptoms and lung function in workers exposed daily to the chemical. Our study used available data from a health screening programme carried out on the workers at a chemical factory in Duxford, England, manufacturing urea formaldehyde resin. ${ }^{5}$

There are three stages to the manufacturing process. Methanol, air, and water are heated with a silver catalyst at $600^{\circ} \mathrm{C}$ to produce formaldehyde; formaldehyde is added to urea, sodium hydroxide, and formic acid and heated to $100^{\circ} \mathrm{C}$ to form urea formaldehyde liquid resin, which is spray dried at $70^{\circ} \mathrm{C}$ to form urea formaldehyde powder resin.

\section{Methods}

POPULATION

All 164 workers who were exposed to free formaldehyde in 1980 have been studied over the subsequent six years, together with a group working on other processes and not in contact with free formaldehyde. This group consisted of 129 personnel working in the bonded structures division at the same factory in 1980 who were not exposed to free formaldehyde but who attended for screening because of exposures to other materials such as phenolic resins, epoxy resins, and carbon fibres.

To investigate whether workers in either group were exposed to agents (apart from formaldehyde in the exposed group) that might affect respiratory function or cause irritation of the respiratory tract, 
Table 1 Other occupational exposures for workers in a factory producing urea formaldehyde (based on random sample of 20 subjects from each group)

\begin{tabular}{lcc}
\hline Exposure & $\begin{array}{l}\text { Group exposed } \\
\text { to formaldehyde }\end{array}$ & $\begin{array}{l}\text { Unexposed } \\
\text { group }\end{array}$ \\
\hline Asbestos & 4 & 11 \\
Carbon and glass fibres & 6 & 20 \\
Silicaceous fillers & 7 & 15 \\
Acid anhydrides & 3 & 1 \\
Aliphatic amines & 7 & 14 \\
Phenol formaldehyde & 12 & $11^{\star}$ \\
Urea formaldehyde & 18 & $5^{\star}$ \\
One or more of the above & 20 & 20 \\
\hline
\end{tabular}

«These men were never exposed to free formaldehyde.

random samples of 20 workers from each group were selected and personnel and safety records assessed. Table 1 shows the results of this enquiry. Data were available on the frequency and level of exposures; none were above recommended limits.

\section{MONITORING OF FORMALDEHYDE CONCENTRATIONS}

Regular atmospheric monitoring began in 1978 . From 1978 to 1985 area samples were collected from representative static locations over periods of between one and six hours. The number of samples collected varied between 28 and 79 in any six month period. From 1985 personal samplers were attached to representative exposed workers for six or seven hours at a time; between 33 and 74 samples were collected in each six month period. Laboratory analysis was by conventional techiques employing chromotropic acid reagent ${ }^{6}$ before 1981 and acetylacetone from 1981 onwards. ${ }^{7}$ Figure 1 shows the results as the geometric mean and maximum during six monthly periods (the results of air sampling after spills, or at the time of other unexpectedly heavy exposures, are not included). The geometric mean of these planned measurements of formaldehyde concentrations rose above $1 \mathrm{ppm}$ only once in these periods and the highest level recorded during the study period was $5.4 \mathrm{ppm}$. There was no evidence

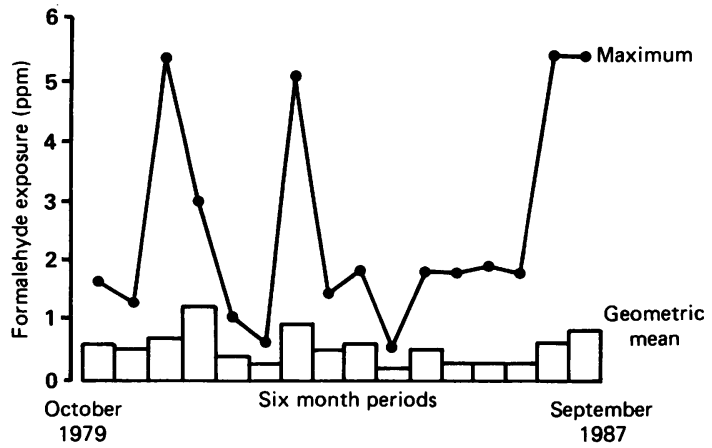

Figure 1 Geometric mean and maximum of representative formaldehyde concentrations obtained during periods of six months from September 1979 to October 1987. of a systematic increase or decrease in exposure over time.

\section{ANNUAL EXAMINATION}

A physical examination is routinely carried out as part of a preplacement assessment in new workers at the factory and a limited examination is part of the annual health assessment. Lung function tests (forced expiratory volume in one second $\left(\mathrm{FEV}_{1}\right)$ and forced vital capacity (FVC)) are performed annually using a dry wedge spirometer (Vitalograph UK); a minimum of three readings are recorded. Tracings have only been accepted for analysis when two readings of $\mathrm{FEV}_{1}$ within 0.11 or $5 \%$ of each other were obtained, the higher reading being used for analysis. Whenever possible, all examinations were carried out at the same time of year for each worker. The same nurse undertook the assessments throughout the study period. The spirometer was checked annually for volume, time calibration, and possible leakage.

\section{FINAL EXAMINATION}

In 1986 a questionnaire on respiratory symptoms and a detailed questionnaire on smoking were completed for workers in both groups in addition to the annual examination. At the same time a work history was obtained by the nurse.

All current workers and those who had left the company (a total of 125 in the exposed group and 95 in the unexposed group) were contacted and asked to attend for the final examination, which was in 1986 (except for nine workers (three exposed, six not exposed) seen in 1987). Six men had died (see below). Out of 65 (39 exposed, 26 not exposed) who had left, 13 (nine exposed, four not exposed) attended; the remainder either could not be contacted or were unable to attend (table 2). A further 10 who did attend had acceptable spirometric traces available for analysis on less than three occasions. Thus there remained 220 (125 exposed, 95 not exposed) men available for analysis, representing $76 \%$ and $74 \%$ of those originally entered into the study.

Table 2 Details of study population

\begin{tabular}{|c|c|c|}
\hline & $\begin{array}{l}\text { Group exposed } \\
\text { to formaldehyde }\end{array}$ & $\begin{array}{l}\text { Unexposed } \\
\text { group }\end{array}$ \\
\hline Entered in study in 1980 & 164 & 129 \\
\hline $\begin{array}{l}\text { Not seen at final assessment: } \\
\text { Left employment } \\
\text { Retired } \\
\text { Died }\end{array}$ & $\begin{array}{r}29(1) \\
1(1) \\
5(1)\end{array}$ & $\begin{array}{r}19(3) \\
3(2) \\
1(1)\end{array}$ \\
\hline $\begin{array}{l}\text { Control exposed to formaldehyde } \\
\text { Acceptable traces on less than }\end{array}$ & - & 5 \\
\hline $\begin{array}{l}\text { three occasions } \\
\text { Available for analysis }\end{array}$ & $\begin{array}{r}4 \\
125\end{array}$ & $\begin{array}{r}6 \\
95\end{array}$ \\
\hline
\end{tabular}

Figures in parentheses refer to subjects with acceptable traces available on more than three occasions. 
Table 3 Details of exposure to formaldehyde (exposed group)

\begin{tabular}{lr}
\hline & No. of subjects $(\%)$ \\
\hline Years exposed before 1980: & $61(49)$ \\
$<10$ & $39(31)$ \\
$10-19$ & $25(20)$ \\
$\geqslant 20$ & \\
Maximum exposure up to end of study: & $21(17)$ \\
Low, constant & $51(41)$ \\
Low with peaks & $9(7)$ \\
Medium, constant & $13(10)$ \\
Medium with peaks & $31(25)$ \\
High exposure & \\
Average exposure over time: & $23(18)$ \\
Low, constant & $60(48)$ \\
Low with peaks & $13(10)$ \\
Medium, constant & $15(12)$ \\
Medium with peaks & $14(11)$ \\
High exposure & 125 \\
Total assessed & \\
\hline
\end{tabular}

\section{EXPOSURE ASSESSMENTS}

The men in the exposed group were classified in terms of their exposure to formaldehyde at different times. Because actual measurements of exposure levels were not available before 1976, exposures were classified on the basis of subjective information collected from staff with a long experience of working conditions. The classification took into account changes in processes and hygiene control during the period and was identical to that used in the mortality study of Acheson et al. ${ }^{8}$ The grade high corresponds to concentrations higher than those encountered under normal working conditions and would be equivalent to about an eight hour time weighted exposure of more than $2.0 \mathrm{ppm}$; medium corresponds to 0.6 to $2.0 \mathrm{ppm}$, and low $(0.1$ to $0.5 \mathrm{ppm})$ to exposures encountered by those working in areas adjacent to the main production areas or in laboratory conditions.

Table 3 presents the assessments of exposure for the 125 workers in the exposed group. By the time of the final examination the maximum exposure at any time was classified as high for $25 \%$ of workers, and medium for a further $17 \%$ of workers. Using a time weighted average of exposure assessments after ranking the assessments on a linear scale, the average exposure assessment was at least medium at a constant concentration in $34 \%$ of workers.

\section{ANALYSIS OF FEV 1 DATA}

For each subject aged 25 years or more in 1980 (117 exposed, 80 unexposed), acceptable $\mathrm{FEV}_{1}$ values were regressed against time (the date of the assessment) and a regression coefficient for the decline in $\mathrm{FEV}_{1}$ calculated (expressed as $\mathrm{ml}$ per year). This analysis was limited to those aged 25 or more in 1980 because younger men were not expected to have experienced a decline in lung function. Values of $\mathrm{FEV}_{1}$ for two workers (one exposed, one unexposed), which were more than 0.51 from their own line of best fit, were omitted and the line recalculated. ${ }^{9}$

The covariates included in the analysis of the rate of decline of $\mathrm{FEV}_{1}$ were $\mathrm{FEV}_{1}$ level (calculated as mean $\mathrm{FEV}_{1} /$ height $^{3}$ ), age in 1980 , smoking state in 1980 and at the final assessment, and for those in the exposed group, the maximum and mean exposure assessment level (ranked on a scale from 1 to 5 ) and the total duration of exposure to formaldehyde.

\section{DEATHS}

Six workers (five exposed, one unexposed) died during the study period; two of the five exposed committed suicide, two died of carcinoma of the bronchus and one of carcinoma of the stomach. The worker in the unexposed group died of a cerebral aneurysm.

\section{Results}

\section{POPULATION CHARACTERISTICS}

Table 4 shows the characteristics of the 220 men in the analysis. The men in the exposed group were on average older than those in the unexposed group, $29 \%$ of the exposed and $39 \%$ of the unexposed being younger than 35 in 1980 . The smoking state of the exposed and unexposed groups was similar both in 1980 and at the final examination when the number of current smokers was $58(46 \%)$ in the exposed group and $43(45 \%)$ in the unexposed group. Those in the exposed group had on average worked for longer in the factory than those in the unexposed group, $22 \%$ compared with $4 \%$ having been employed for 20 years or more. Of those in the exposed group, 103 $(82 \%)$ had been exposed to formaldehyde throughout their time of employment at the factory.

RESPIRATORY SYMPTOMS AT THE FINAL ASSESSMENT

None of the 125 workers in the exposed group and only four (4\%) of the 95 in the unexposed group had

Table 4 Characteristics of study population in 1980

\begin{tabular}{lcc}
\hline & $\begin{array}{l}\text { Group exposed to } \\
\text { formaldehyde No (\%) }\end{array}$ & $\begin{array}{l}\text { Unexposed group } \\
\text { No }(\%)\end{array}$ \\
\hline Age $(y):$ & & \\
$15-24$ & $8(6)$ & $15(16)$ \\
$25-34$ & $29(23)$ & $22(23)$ \\
$35-44$ & $44(35)$ & $33(35)$ \\
$45-54$ & $29(23)$ & $18(19)$ \\
$\geqslant 55$ & $15(12)$ & $7(7)$ \\
Smoking state: & & \\
Current smoker & $67(54)$ & $54(57)$ \\
Ex-smoker & $26(21)$ & $22(23)$ \\
Never smoked & $32(26)$ & $19(20)$ \\
Years worked in factory: & & \\
$<10$ & $58(46)$ & $66(70)$ \\
$10-19$ & $40(32)$ & $25(26)$ \\
20 or more & $27(22)$ & $4(4)$ \\
Total assessed & 125 & 95 \\
\hline
\end{tabular}



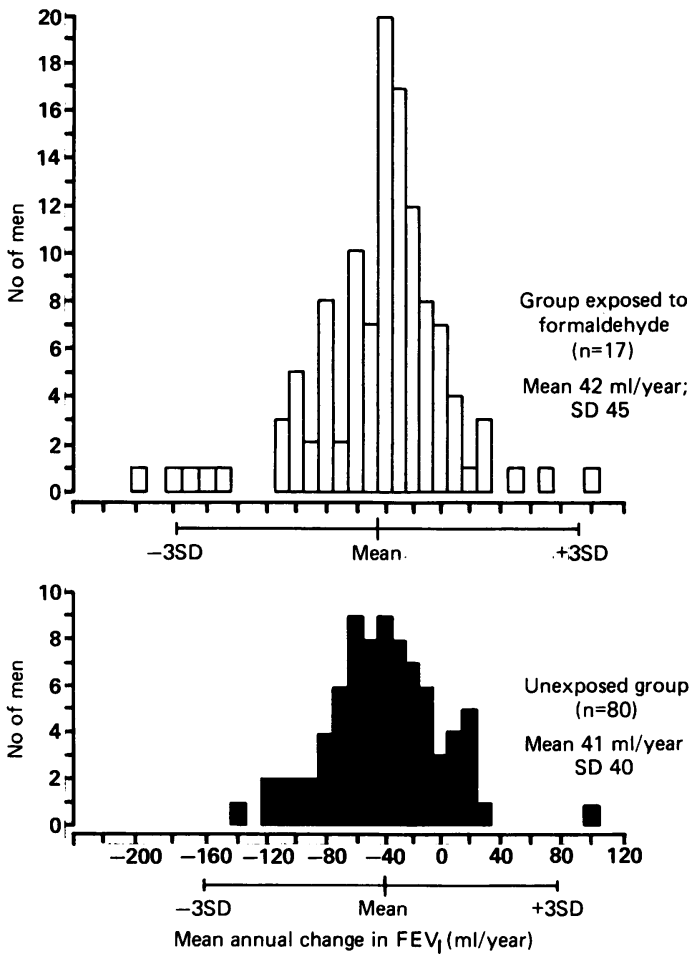

Figure 2 Distribution of rate of decline of FEV, in exposed and unexposed groups.

chronic bronchitis, defined as a history of sputum production for at least three months in the year. ${ }^{10}$ Shortness of breath when hurrying or walking uphill was reported by $15(12 \%)$ and $15(16 \%)$. Although wheezing was slightly more common in the exposed group $(26 \%)$ than in the unexposed group $(20 \%)$, only three $(2 \%)$ and five $(5 \%)$ wheezed on most days or nights; $12 \%$ and $11 \%$ reported a history of other chest illnesses. Thus there was no evidence to suggest that respiratory symptoms were more common in those exposed to formaldehyde.

DECLINE IN FEV

All workers included in the analysis had acceptable $\mathrm{FEV}_{1}$ traces on a minimum of three occasions; $69 \%$ of the exposed and $71 \%$ of the unexposed group had traces available on at least five occasions $(40 \%$ and $41 \%$ on six occasions and $15 \%$ and $12 \%$ on seven occasions).

When compared with age and height specific reference values of $\mathrm{FEV}_{1}{ }^{11}$ the first acceptable $\mathrm{FEV}_{1}$ was within 0.51 (equivalent to approximately one standard deviation) of the predicted value in $65 \%$ of the exposed and $59 \%$ of the unexposed workers. For $9 \%$ of the exposed group and $11 \%$ of the unexposed group the observed value was more than $0.5 \cdot 1$ below the predicted value.
Table 5 Decline in FEV, with age by exposure group and smoking history (in workers aged 25 or older in 1980)

\begin{tabular}{|c|c|c|c|c|}
\hline \multirow[b]{2}{*}{$\begin{array}{l}\text { Smoking state at } \\
\text { final assessment }\end{array}$} & \multicolumn{2}{|c|}{$\begin{array}{l}\text { Group exposed to } \\
\text { formaldehyde }\end{array}$} & \multicolumn{2}{|c|}{ Unexposed group } \\
\hline & No & $\begin{array}{l}\text { Mean slope } \\
m l / y(95 \% C I)\end{array}$ & No & $\begin{array}{l}\text { Mean slope } \\
m l / y(95 \% C I)\end{array}$ \\
\hline $\begin{array}{l}\text { Never smoked } \\
\text { Ex-smoker } \\
\text { Current smoker } \\
\text { Total }\end{array}$ & $\begin{array}{r}26 \\
34 \\
57 \\
117\end{array}$ & $\begin{array}{l}45(28-62) \\
33(20-46) \\
46(33-59) \\
42(34-51)\end{array}$ & $\begin{array}{l}13 \\
31 \\
36 \\
80\end{array}$ & $\begin{array}{l}29(7-51) \\
40(26-54) \\
46(32-61) \\
41(32-50)\end{array}$ \\
\hline
\end{tabular}

The distribution of the regression coefficients of the decline in $\mathrm{FEV}_{1}$ with age is shown in fig 2. The mean decline was $42 \mathrm{ml}$ a year (SD $45 \mathrm{ml}$ a year) in the exposed group and $41 \mathrm{ml}$ a year (SD $40 \mathrm{ml}$ a year) in the unexposed group. Outlying points in the distribution (defined as more than three SDs above or below the mean value) occurred in three of the exposed group and one of the unexposed group. Two current smokers (both exposed group) had declines of 185 and $205 \mathrm{ml} /$ year; one ex-cigarette smoker, currently smoking cigars (unexposed group), had a yearly increase of $104 \mathrm{ml} /$ year and one lifelong nonsmoker (exposed group) had a yearly increase of 96 $\mathrm{ml} /$ year. Only one (exposed group) of the workers with a rate of decline outside three standard deviations had less than four measurements of $\mathrm{FEV}_{1}$. None of the covariates analysed was significantly associated with the rate of decline.

The rates of decline in the never smoker, exsmoker, and current smoker subgroups of the unexposed group showed the expected association with smoking, the fastest decline occurring in current smokers (table 5). In contrast, the mean rate of decline for those who had never smoked in the exposed group was similar to that for smokers. There was, however, a relatively small number of workers who had never smoked and considerable variation in the rate of decline between subjects so the confidence limits on the mean rate of decline were large (table 5).

\section{Discussion}

There is no evidence, from our study, of an excess of respiratory symptoms or an accelerated rate of fall of $\mathrm{FEV}_{1}$ in workers exposed to formaldehyde compared with a group who were not exposed. None of the 125 workers in the formaldehyde group reported symptoms consistent with chronic bronchitis; also shortness of breath in the exposed group when hurrying or walking up hill (reported by $12 \%$ ) was no more common than in the 95 workers in the unexposed group $(16 \%)$. The mean annual decline in $\mathrm{FEV}_{1}$ with age was similar in the two groups, $42 \mathrm{ml}$ a year in the group exposed to formaldehyde and $41 \mathrm{ml}$ a year in the unexposed group. No association was found 
between mean annual decline in FEV 1 and level or duration of exposure to formaldehyde.

Analysis of the decline in $\mathrm{FEV}_{1}$ in relation to smoking history showed the expected relation in the unexposed group, with a mean rate of decline of 29 , 40 , and $46 \mathrm{ml}$ a year for those who had never smoked, ex-smokers, and current smokers. This was consistent with findings from other studies. ${ }^{9}$ In the formaldehyde group, however, the same trend was not seen. The rate of decline in those who had never smoked (45 ml a year) was similar to that in current smokers (46 ml a year); whereas ex-smokers had a decline of 33 $\mathrm{ml}$ a year. A recent study on Swedish woodworkers exposed to formaldehyde demonstrated a significant mean decline in forced expiratory flow $\left(\mathrm{FEF}_{25-75}\right)$ over five years in 11 non-smokers $(0.211 / \mathrm{s} /$ year $)$ but not in 10 smokers $(0.06 \mathrm{l} / \mathrm{s} /$ year $) .{ }^{12} \mathrm{~A}$ significant decline in the $\mathrm{FEV}_{1} / \mathrm{FVC}$ ratio of $0.45 \%$ a year was also reported in the non-smokers but not in the smokers. ${ }^{12}$ In a five year study of workers employed in the manufacture of toluene di-isocyanate an excess decline in $\mathrm{FEV}_{1}$ in non-smokers with high exposure to the compound has been reported when compared with current and ex-smokers. ${ }^{13}$ These findings and those of the present study are consistent with the hypothesis that susceptibility to the effect of these chemicals on the respiratory tract may be greater in non-smokers than in smokers or, at least, that there is no additional effect of smoking on exposure.

In interpreting these results it is important to assess any possible bias in the conduct of the study that might prevent a real difference between the exposed and unexposed groups from being detected. The group was based on all those working in the factory in 1980, not a cohort defined by year of first employment. It is, therefore, part of a much larger cohort employed over many years, some of whom were likely to have been exposed to much higher concentrations of formaldehyde in the past. Workers with adverse respiratory effects from high concentrations may have left employment early so that only "survivors" would be included in the study.

Workers in the chemical industry may be exposed to many potentially harmful substances. A detailed analysis of exposures experienced by a random sample of the group not exposed to formaldehyde suggested that any such exposures were well within current recommended limits. Comparison with this group, however, may represent a source of bias as their lung function may have been reduced by such exposures, thus leading to an underestimate of any decline associated with exposure to formaldehyde. As the rates of decline in $F_{E V}$ in the unexposed group were similar to those in other studies of workers not in the chemical industry, however, such exposure is unlikely to have been important.

Another potential source of bias is a possible difference in the respiratory health between exposed and control workers not seen at the final assessment because they had left employment and could not be traced or were unable to attend. Of 12 men in the exposed group not seen, the $\mathrm{FEV}_{1}$ at the start of the study was less than predicted in nine $(75 \%)$ compared with $42(36 \%)$ of the 117 who were included in the main analysis. In the unexposed group nine $(33 \%)$ of 27 who were not seen at the final assessment had an initial FEV that $_{1}$ was less than predicted compared with $36(45 \%)$ of 80 who were seen.

Variability in $\mathrm{FEV}_{1}$ measurement represents another potential source of bias that could result in no difference being observed between the groups. Although the study was based on routine screening, efforts were made to minimise bias of this kind. The same nurse was used throughout and all traces were reread at the end of the study by two trained observers. The variation in the rate of decline in FEV 1 was similar to that found by Fletcher and his colleagues in their longitudinal study of London transport workers-namely, a standard deviation of approximately $40 \mathrm{ml}$ a year'-suggesting that the technique was adequate to detect important differences.

It is of interest that three men in the formaldehyde group but none in the unexposed group died of carcinoma. The workers exposed to formaldehyde, although comparable in smoking habits to the controls, were on average somewhat older. The large occupational cohort study by Acheson $e t$ ald not support the hypothesis that formaldehyde is a carcinogen in humans although they indicated that further studies on those exposed to "high" levels for more than five years were needed.

In conclusion, this longitudinal study has not found evidence of an excess of respiratory symptoms, or an accelerated decline in $\mathrm{FEV}_{1}$ in workers currently exposed to formaldehyde when compared to an unexposed group. The suggestion of a possible adverse effect in non-smokers is consistent with findings in a study of workers exposed to formaldehyde and toluene di-isocyanate ${ }^{13}$ and deserves to be investigated further.

We are grateful to Ciba-Geigy Plastics, Duxford, for their help and cooperation, in particular to $\mathrm{Mr} S$ Dwyer, occupational hygienist and Sister L Hodgson, lately senior nursing officer. We also thank Patrick Kelleher and Deborah Johnson for help with assessment of the Vitalograph traces and analysis of the data.

1 Clayton GD, Clayton FE. Patty's Industrial Hygiene and Toxicology, 3rd ed. Volume 2A. New York: John Wiley and Sons, 1981:2637-46.

2 Hendrick DG, Lane DJ. Occupational formalin asthma. Br J Ind Med 1977;34:11-8.

3 Bracken MJ, Leasa DJ, Morgan WKC. Exposure to formaldehyde. Relationship to respiratory symptoms and function. Can J Public Health 1985;76:312-6. 
4 Sardinas AV, Most RS, Guilietti MA, Honchar P. Health effects associated with urea formaldehyde foam insulation in Connecticut. J Environ Sci Health 1979;41:270-2.

5 Craigen AA. The control of dermatitis in a plastics factory. $J$ Soc Occup Med 1975;25:127-2.

6 DHEW. Formaldehyde in air. Method 125. In: National Institute for Occupational Safety and Health. manual of analytical methods. 2nd ed. Vol 1. Washington: US Department of Health Education and Welfare, 1977:125/1;125/9. (DHEW (NIOSH) publ No 77-157-A).

7 Nash TJ. The colorimetric determination of formaldehyde by means of the Hantzch reaction. Biochemistry 1955;55:416-21.

8 Acheson ED, Barnes HR, Gardner MJ, Osmond C, Pannett B, Taylor CP. Formaldehyde in the British chemical industry. Lancet 1984;i:611-6.

9 Fletcher C, Peto R, Tinker C, Speizer FE. The natural history of chronic bronchitis and emphysema. Oxford: Oxford University
Press, 1976:179-81.

10 Medical Research Council. Definition and classification of chronic bronchitis for clinical and epidemiological purposes. A report to the Medical Research Council by their committee on the aetiology of chronic bronchitis. Lancet 1965;i:775.

11 Kory RC, Callahan R, Boren HG, Syner JC. The Veterans Administration Army cooperative study of pulmonary function. 1 Clinical spirometry in normal men. Am J Med 1961;30:243-58.

12 Alexandersson R, Hedenstierna G. Pulmonary function in wood workers exposed to formaldehyde: A prospective study. Arch Environ Health 1989;44:5-11.

13 Diem JE, Jones RN, Hendrick DJ, et al. Five year longitudinal study of workers employed in a new toluene diisocyanate manufacturing plant. Am Rev Respir Dis 1982;126:420-8.

Accepted 3 April 1990

\section{Vancouver style}

All manuscripts submitted to the $B r J$ Ind Med should conform to the uniform requirements for manuscripts submitted to biomedical journals (known as the Vancouver style)

The $\mathrm{Br} J$ Ind Med, together with many other international biomedical journals, has agreed to accept articles prepared in accordance with the Vancouver style. The style (described in full in $\mathrm{Br}$ Med J, 24 February 1979, p 532) is intended to standardise requirements for authors.

References should be numbered consecutively in the order in which they are first mentioned in the text by Arabic numerals above the line on each occasion the reference is cited (Manson ${ }^{1}$ confirmed other reports ${ }^{2-5} \ldots$.). In future references to papers submitted to the BrJ Ind Med should include: the names of all authors if there are six or less or, if there are more, the first three followed by et al; the title of journal articles or book chapters; the titles of journals abbreviated according to the style of Index Medicus; and the first and final page numbers of the article or chapter.

Examples of common forms of references are:

1 International Steering Committee of Medical Editors. Uniform requirements for manuscripts submitted to biomedical journals. Br Med J 1979;1:532-5.

2 Soter NA, Wasserman SI, Austen KF. Cold urticaria: release into the circulation of histamine and eosino-phil chemotactic factor of anaphylaxis during cold challenge. $N \mathrm{Engl}$ J Med 1976;294:687-90

3 Weinstein L, Swartz MN. Pathogenic properties of invading micro-organisms. In: Sodeman WA Jr, Sodeman WA, eds. Pathologic physiology: mechanisms of disease. Philadelphia: W B Saunders, 1974:457-72. 